\title{
Yield stability of winter wheat cultivars under diversified chemical weed control
}

\author{
Stabilność plonowania odmian pszenicy ozimej \\ w warunkach zróżnicowanej ochrony herbicydowej
}

\author{
Renata Kieloch, Ryszard Weber
}

\section{Summary}

The field experiments were carried out during 2007-2009 to evaluate the effect of different chemical weed control on yield stability of three winter wheat cultivars (Tonacja, Satyna, Bogatka). Plants were sprayed with Quarz Super 550 SC (2.5 I/ha), Mustang 306 SE (0.6 l/ha), Chwastox Trio 540 SL (2 l/ha) and Lintur 70 WG (180 g/ha). Herbicide treatments were made in the spring, when wheat was at the stage of full tillering. At the time of harvest grain yield was recorded. Discriminant analysis was used for evaluation of yield variability. Under the diversified chemical weed control Satyna cultivar provided the highest grain yield compared to others varieties. Yield stability of examined cultivars was significantly diversified and dependent on cultivar genotype. The herbicide Mustang 306 SE decreased grain yield of Satyna cultivar compared to untreated object. In turn, Lintur 70 WG and Quarz Super 550 SC application resulted in increase of Tonacja cultivar yield.

Key words: winter wheat, cultivars, herbicides, yield, yield variability, Kangs' measure

\section{Streszczenie}

W latach 2007-2009 wykonano badania polowe nad oceną wpływu zróżnicowanej ochrony chemicznej przed chwastami na stabilność plonowania trzech odmian pszenicy ozimej (Tonacja, Satyna, Bogatka). Uwzględniono herbicydy: Quarz Super 550 SC (2,5 l/ha), Mustang 306 SE (0,6 l/ha), Chwastox Trio 540 SL (2 l/ha) and Lintur 70 WG (180 g/ha). Zabiegi wykonano wiosną, w fazie pełni krzewienia pszenicy ozimej. W czasie zbioru oznaczono wysokość plonu ziarna. Do oceny zmienności plonowania wykorzystano metodę analizy dyskryminacyjnej. W warunkach zróżnicowanych zabiegów herbicydowych odmiana Satyna cechowała się wyższym plonowaniem $w$ porównaniu do pozostałych odmian. Stabilność plonowania badanych odmian w zróżnicowanych wariantach herbicydowych była znacznie zróżnicowana i uzależniona od genotypu odmiany. Herbicyd Mustang 306 SE obniżył plonowanie odmiany Satyna w porównaniu do kontroli. Z kolei po zastosowaniu środków Lintur 70 WG i Quarz Super 550 SC uzyskano wzrost plonowania odmiany Tonacja.

Słowa kluczowe: pszenica ozima, odmiany, herbicydy, plon, zmienność plonowania, miara Kanga

Instytut Uprawy Nawożenia i Gleboznawstwa - Państwowy Instytut Badawczy

Zakład Herbologii i Technik Uprawy Roli

Orzechowa 61, 50-540 Wrocław

r.kieloch@iung.wroclaw.pl 


\section{Wstęp / Introduction}

Potencjał plonotwórczy uprawianej odmiany pszenicy ozimej podyktowany jest jej właściwościami genetycznymi, ale może kształtować się różnie w zróżnicowanych warunkach siedliska oraz technologii produkcji. Dzięki zabiegom herbicydowym możliwe jest utrzymanie zasiewów pszenicy ozimej w stanie wolnym od chwastów, co pozwala znacznie ograniczyć straty w plonach wywołane ich konkurencyjnym oddziaływaniem. Jednak praktyka rolnicza oraz badania naukowe wskazują również na ujemny aspekt stosowania herbicydów, ponieważ mogą być one nie w pełni selektywne dla rośliny uprawnej. Objawia się to uszkodzeniami roślin, a w skrajnych przypadkach stratami w plonach. Wpływ herbicydu na pszenicę ozimą może być zróżnicowany, w zależności od stopnia tolerancji uprawianej odmiany (Adamczewski i Urban 2000; Kieloch 2007). Ze względu na częste przypadki uszkodzeń plantacji pszenicy ozimej przez herbicydy, znaczącą rolę $\mathrm{w}$ doborze środka do odchwaszczania jej upraw odgrywa znajomość selektywności herbicydu w stosunku do uprawianej odmiany. Innym ważnym kryterium decydującym o wyborze odpowiedniego herbicydu do odchwaszczania odmiany pszenicy powinna być zmienność jej plonowania w zróżnicowanych warunkach środowiska i z zastosowaniem różnej ochrony chemicznej przed chwastami.

Ocena stabilności plonowania odmian w zmiennych warunkach produkcyjnych może być pomocna przy doborze odmian do uprawy w zależności od stosowanej agrotechniki, czy też przy wyborze genotypów zaadaptowanych do specyficznych warunków klimatycznych bądź siedliskowych. Ocena interakcji genotypowo-środowiskowej najczęściej dokonywana jest za pomocą analizy stabilności genotypów. Porównania reakcji badanych genotypów w zmieniających się warunkach środowiska do wzorca stabilności rolniczej można przeprowadzać wieloma metodami o różnym stopniu komplikacji (Kang 1998; Mądry i Kang 2005). Metody te pozwalają na stwierdzenie, czy dana odmiana zachowuje się stabilnie, czy niestabilnie w zmieniających się warunkach środowiskowych. Preferowane są odmiany o szerokiej adaptacji do zmiennych warunków środowiska i agrotechniki.

W pracy oceniono zmienność plonowania, w warunkach Dolnego Śląska, trzech aktualnie uprawianych odmian pszenicy ozimej (Tonacja, Satyna, Bogatka) pod wpływem herbicydów.

\section{Materiały i metody / Materials and methods}

W latach 2007-2009, we wsi Iwiny (województwo dolnośląskie) badano zmienność plonowania wybranych odmian pszenicy ozimej w zależności od rodzaju stosowanego herbicydu. Doświadczenia założono z trzema odmianami pszenicy ozimej: Tonacja, Satyna i Bogatka w układzie split-plot, w czterech powtórzeniach. Pszenicę wysiano $\mathrm{w}$ pierwszej dekadzie października w sezonach 2006/2007 i 2007/2008 oraz na początku drugiej dekady października w sezonie 2008/2009. Czynnikiem doświadczalnym pierwszego rzędu były odmiany pszenicy ozimej.
W ramach czynnika pierwszego rozlosowywano obiekty czynnika drugiego - herbicydy: a. kontrola, b. Quarz Super $550 \mathrm{SC}$ (diflufenikan + izoproturon) $(2,5 \mathrm{l} / \mathrm{ha})$, c. Mustang 306 SE (2,4-D + florasulam) $(0,6$ l/ha $), d$. Chwastox Trio $540 \mathrm{SL}$ (mekoprop + MCPA + dikamba) (2 1/ha), e. Lintur $70 \mathrm{WG}$ (dikamba + triasulfuron) (180 g/ha). Stosowano je wiosna, $w$ fazie pełni krzewienia pszenicy ozimej. Powierzchnia każdego poletka w doświadczeniu wynosiła $16 \mathrm{~m}^{2}$. Przed zastosowaniem środków chemicznych przeprowadzano ręcznie odchwaszczanie na każdym poletku. Wszystkie zabiegi agrotechniczne wykonano zgodnie z wymaganiami dla pszenicy ozimej. Zbiór ziarna wykonano w fazie dojrzałości pełnej, gdzie ustalono wielkość plonu w przeliczeniu na 14\% wilgotności. Plony badanych odmian w każdym doświadczeniu, w warunkach zróżnicowanych substancji czynnych herbicydów porównywano z obiektem kontrolnym odchwaszczanym ręcznie.

Analizę statystyczną wykonano przy użyciu programów Sergen 4 i Explan. Przeprowadzona analiza statystyczna przy pomocy tych programów jest wykorzystywana do oceny zmienności plonowania odmian roślin uprawnych $\mathrm{z}$ określonymi wzorcami. W przedstawionej pracy wzorcem jest obiekt kontrolny nieopryskiwany środkiem chemicznym. Wszelkie porównania wariantów herbicydowych w poszczególnych tabelach odnoszą się do obiektu kontrolnego. Ostatnia kolumna tabel 2., 3. i 4. przedstawia miarę stabilności Kanga. Miara Kanga jest najczęściej stosowana do analizy stabilności plonowania określonych genotypów poprzez ocenę ich szerokiej adaptacji w danym rejonie uprawy. Jest ona kombinacją wartości dwóch parametrów - średniej genotypowej z badanych środowisk i wariancji stabilności. W opisanym doświadczeniu miara Kanga jest kombinacją wartości średniego plonu $\mathrm{z}$ trzech lat badań oraz wariancji stabilności (zmienności tych plonów) przy danym wariancie herbicydowym. Obiekty doświadczenia (plony odmiany $\mathrm{w}$ warunkach stosowania określonego herbicydu) o najwyższych wartościach miary Kanga uznaje się za najlepiej zaadaptowane do zmiennych warunków atmosferycznych. Obiekty te wykazują wysokie i stabilne plony w analizowanych trzech latach badań, w warunkach zastosowania określonego herbicydu.

\section{Wyniki i dyskusja / Results and discussion}

Plonowanie badanych odmian pszenicy ozimej w warunkach różnych zabiegów herbicydowych charakteryzowało się znacznym zróżnicowaniem (tab. 1). Istotnie wyższym plonem w porównaniu do odmiany Bogatka odznaczała się odmiana Satyna. Średnie plony trzech odmian po zastosowaniu badanych herbicydów nie różniły się istotnie od obiektu kontrolnego. Istotna wartość interakcji odmiany $\mathrm{z}$ herbicydem wskazuje jednak na znaczne różnice w reakcji poszczególnych odmian na zastosowane środki chemiczne.

Herbicydy Lintur 70 WG i Quarz Super 550 SC przyczyniły się do wyższych plonów odmiany Tonacja w porównaniu do obiektu kontrolnego (tab. 2). Wartości statystyki F dla interakcji plonów z latami badań wskazują na wyrównane plony tej odmiany w poszczególnych latach badań niezależnie od stosowanego herbicydu. Również na 
Tabela 1. Zmienność plonowania odmian pszenicy ozimej w zależności od rodzaju herbicydu [t/ha]

Table 1. Yield variability of winter wheat cultivars depending on herbicide [t/ha]

\begin{tabular}{l|c|c|c|c}
\hline Obiekty - Treatments & Tonacja & Satyna & Bogatka & Średnia - Mean \\
\hline Kontrola - Check & 9,7 & 10,29 & 9,70 & 9,90 \\
\hline Chwastox Trio 540 SL & 9,91 & 10,4 & 9,61 & 9,97 \\
\hline Lintur 70 WG & 9,98 & 10,32 & 9,73 & 10,01 \\
\hline Mustang 306 SE & 9,82 & 10,03 & 9,53 & 9,79 \\
\hline Quarz Super 550 SE & 9,96 & 10,12 & 9,77 & 9,95 \\
\hline
\end{tabular}

Tabela 2. Zmienność plonowania odmiany Tonacja w zależności od stosowanego herbicydu

Table 2. Yield variability of Tonacja cultivar depending on herbicide

\begin{tabular}{l|c|c|c|c|c}
\hline $\begin{array}{c}\text { Obiekty } \\
\text { Treatments }\end{array}$ & $\begin{array}{c}\text { Średni plon } \\
\text { Average yield } \\
{[\mathrm{t} / \mathrm{ha}]}\end{array}$ & $\begin{array}{c}\text { Ocena efektu } \\
\text { głównego } \\
\text { Main effect } \\
\text { evaluation }\end{array}$ & $\begin{array}{c}\text { F dla efektu } \\
\text { głównego } \\
\text { F for main effect }\end{array}$ & $\begin{array}{c}\text { F dla interakcji } \\
\text { lata } \times \text { herbicydy } \\
\text { F for interaction } \\
\text { years } \times \text { herbicides }\end{array}$ & $\begin{array}{c}\text { Stabilność Kanga } \\
\text { Kangs' stability } \\
\text { YS }\end{array}$ \\
\hline Kontrola - Check & 9,70 & 0,00 & - & 0,00 & 0 \\
\hline Chwastox Trio 540 SL & 9,91 & 0,208 & 1,73 & 0,88 & $4^{*}$ \\
\hline Lintur 70 WG & 9,98 & 0,284 & $93,62^{* *}$ & 0,03 & $6^{*}$ \\
\hline Mustang 306 SE & 9,82 & 0,119 & 0,86 & 0,58 & 1 \\
\hline Quarz Super 550 SE & 9,96 & 0,257 & $11,66^{*}$ & 0,20 & $5^{*}$ \\
\hline
\end{tabular}

Wartość graniczna - Boundary value YS $=3,2$

Istotność na poziomie $* \alpha=0,05,{ }^{*} \alpha=0,01-$ Significance at level ${ }^{*} \alpha=0.05,{ }^{*} \alpha=0.01$

$\mathrm{F}$ - statystyka F - F statistics

Tabela 3. Zmienność plonowania odmiany Satyna w zależności od stosowanego herbicydu

Table 3. Yield variability of Satyna cultivar depending on herbicide

\begin{tabular}{l|c|c|c|c|c}
\hline $\begin{array}{c}\text { Obiekty } \\
\text { Treatments }\end{array}$ & $\begin{array}{c}\text { Średni plon } \\
\text { Average yield } \\
\text { [t/ha] }\end{array}$ & $\begin{array}{c}\text { Ocena efektu } \\
\text { głównego } \\
\text { Main effect } \\
\text { evaluation }\end{array}$ & $\begin{array}{c}\text { F dla efektu } \\
\text { głównego } \\
\text { F for main effect }\end{array}$ & $\begin{array}{c}\text { F dla interakcji } \\
\text { lata } \times \text { herbicydy } \\
\text { F for interaction } \\
\text { years } \times \text { herbicides }\end{array}$ & $\begin{array}{c}\text { Stabilność Kanga } \\
\text { Kangs' stability }- \\
\text { YS }\end{array}$ \\
\hline Kontrola - Check & 10,29 & 0,000 & - & - & $4^{*}$ \\
\hline Chwastox Trio 540 SL & 10,40 & 0,109 & 0,24 & 1,71 & $6^{*}$ \\
\hline Lintur 70 WG & 10,32 & 0,029 & 0,01 & $4,60^{*}$ & -3 \\
\hline Mustang 306 SE & 10,03 & $-0,262$ & $7,70^{*}$ & 0,31 & -4 \\
\hline Quarz Super 550 SE & 10,12 & $-0,164$ & 1,13 & 0,84 & 0 \\
\hline
\end{tabular}

Wartość graniczna - Boundary value YS $=0,8$

Istotność na poziomie $* \alpha=0,05-$ Significance at level $* \alpha=0.05$

$\mathrm{F}$ - statystyka $\mathrm{F}$ - F statistics

Tabela 4. Zmienność plonowania odmiany Bogatka w zależności od stosowanego herbicydu

Table 4. Yield variability of Bogatka cultivar depending on herbicide

\begin{tabular}{l|c|c|c|c|c}
\hline $\begin{array}{c}\text { Obiekty } \\
\text { Treatments }\end{array}$ & $\begin{array}{c}\text { Średni plon } \\
\text { Average yield } \\
\text { (t/ha) }\end{array}$ & $\begin{array}{c}\text { Ocena efektu } \\
\text { głównego } \\
\text { Main effect } \\
\text { evaluation }\end{array}$ & $\begin{array}{c}\text { F dla efektu } \\
\text { głównego } \\
\text { F for main effect }\end{array}$ & $\begin{array}{c}\text { F dla interakcji } \\
\text { lata } \times \text { herbicydy } \\
\text { F for interaction } \\
\text { years } \times \text { herbicides }\end{array}$ & $\begin{array}{c}\text { Stabilność Kanga } \\
\text { Kangs' stability } \\
\text { YS }\end{array}$ \\
\hline Kontrola - Check & 9,70 & 0,00 & - & 0,00 & $3^{*}$ \\
\hline Chwastox Trio 540 SL & 9,61 & $-0,051$ & 0,07 & 0,23 & -1 \\
\hline Lintur 70 WG & 9,73 & 0,026 & 0,78 & 0,03 & $5^{*}$ \\
\hline Mustang 306 SE & 9,53 & $-0,170$ & 2,97 & 0,34 & 0 \\
\hline Quarz Super 550 SE & 9,77 & 0,072 & 0,63 & 0,29 & $6^{*}$ \\
\hline
\end{tabular}

Istotność na poziomie $* \alpha=0,05-$ Significance at level $* \alpha=0.05$

$\mathrm{F}$ - statystyka F - F statistics 
podstawie miary Kanga można stwierdzić, że spośród badanych środków: Lintur 70 WG, Quarz Super 550 SC i Chwastox Trio 540 SL przyczyniły się do wyrównanych i wysokich plonów odmiany Tonacja w porównaniu do pozostałych kombinacji opryskiwanych herbicydami.

Analizując zmienność plonowania odmiany Satyna w warunkach różnych substancji czynnych stwierdzono istotny spadek plonów ziarna w porównaniu do obiektu kontrolnego pod wpływem herbicydu Mustang 306 SE (tab. 3). Pozostałe herbicydy nie spowodowały obniżenia plonowania badanej odmiany. Herbicyd Lintur 70 WG przyczynił się do istotnej zmienności plonowania odmiany Satyna w analizowanych latach badań. W przypadku aplikacji pozostałych środków, odmiana ta dawała stabilne plony w latach badań. Wysoka wartość miary Kanga dla herbicydu Chwastox Trio 540 SL wskazuje, że wymieniony środek chemiczny powinien być zalecany w uprawie tej odmiany.

Nie stwierdzono istotnych różnic w plonowaniu odmiany Bogatka w warunkach kontroli i wariantów herbicydowych (tab. 4). Statystyka F dla interakcji plonu $\mathrm{z}$ latami $\mathrm{w}$ ramach danej kombinacji herbicydowej nie wykazała również istotnego wpływu herbicydów na zróżnicowanie plonów tej odmiany w trzech latach badań. Wysoka wartość miary Kanga wykazała jednak, że wysokie i stabilne plonowanie tej odmiany uzyskano na poletkach opryskiwanych herbicydami Quarz Super 550 SC i Lintur 70 WG.

Wykonana analiza statystyczna wykazała znaczną zmienność plonów ocenianych odmian pszenicy ozimej. $\mathrm{W}$ warunkach stosowania różnych herbicydów, $\mathrm{z}$ uwzględnieniem obiektu kontrolnego, najwyżej plonowała odmiana Satyna, zaś odmiany Tonacja i Bogatka dawały podobne plony. Wykazana zmienność plonów była spowodowana odmienną reakcją poszczególnych odmian pszenicy na zastosowane środki ochrony roślin. Zróżnicowana tolerancja odmian pszenicy ozimej na herbicydy wynika głównie $\mathrm{z}$ właściwości genetycznych danej odmiany, jednak może być w znacznym stopniu modyfikowana przez warunki klimatyczno-glebowe. Obserwowano obniżoną tolerancję odmian pszenicy na niektóre środki w warunkach niesprzyjających jej wegetacji, tj. długotrwała susza, chłodna i wilgotna wiosna, mroźna i bezśnieżna zima, co wyrażało się znacząco niższym plonowaniem. Z kolei w latach o korzystnym przebiegu pogody ujemna reakcja tych odmian nie wystapiła (Kieloch i Rola 2007, 2010).

Miara Kanga (YS - yield-stability ) jest powszechnie stosowana do oceny stabilności plonowania poszczególnych odmian poprzez ocenę jej adaptacji do warunków panujących w danym regionie uprawy (Kang 1997). Na podstawie przedstawionych wyników można stwierdzić, że odmiany reagowały odmiennie na stosowane środki chemiczne $\mathrm{w}$ okresie trzech analizowanych lat. Odmiana Tonacja odznaczała się wysokimi i stabilnymi plonami w warunkach ochrony herbicydem Lintur 70 WG. Odmiana Satyna wykazywała wysokie i stabilne plony po zastosowaniu herbicydu Chwastox Trio 540 SL, a odmiana Bogatka po aplikacji herbicydu Quarz Super 550 SC.

\section{Wnioski / Conclusions}

1. W warunkach zróżnicowanych zabiegów herbicydowych odmiana Satyna odznaczała się wyższym plonowaniem w porównaniu do pozostałych odmian.

2. Stabilność plonów badanych odmian w zróżnicowanych wariantach herbicydowych, w trzech latach badań była znacznie zróżnicowana i uzależniona od genotypu odmiany.

3. Herbicyd Mustang 306 SE wpłynął na obniżenie plonów odmiany Satyna w porównaniu do kontroli bez zabiegów ochrony roślin. Środki Lintur 70 WG i Quarz Super 550 SC przyczyniły się do wyższych plonów odmiany Tonacja w porównaniu do obiektu kontrolnego.

Opracowanie wykonano w ramach zadania $2.6 \mathrm{w}$ programie wieloletnim Instytutu Uprawy Nawożenia i Gleboznawstwa - Państwowego Instytutu Badawczego.

\section{Literatura / References}

Adamczewski K., Urban M. 2000. Reakcja 7 odmian pszenicy ozimej na dwie formy użytkowe chlorotoluronu. [Reaction of 7 winter wheat cultivars on two forms of chlorotoluron]. Prog. Plant Prot./Post. Ochr. Roślin 40 (1): 374-379.

Kang M.S. 1997. Using genotype-by-environment interaction for crop cultivar development. Adv. Agron. 62: 200-252.

Kieloch R. 2007. Oddziaływanie herbicydów na odmiany zbóż. Studia i Raporty IUNCr - PIB 8: 65-76.

Kieloch R., Rola H. 2007. Ocena tolerancji wybranych odmian pszenicy ozimej na herbicydy. [The evaluation of tolerance of selected winter wheat cultivars to herbicides]. Prog. Plant Prot./Post. Ochr. Roślin 47 (3): 133-137.

Kieloch R., Rola H. 2010. Sensitivity of winter wheat cultivars to selected herbicides. J. Plant Prot. Res. 50 (1): 35-40.

Mądry W., Kang M.S. 2005. Scheffe-Caliński and Shukla Models: Their Interpretation and usefulness in stability and adaptation analyses. J. Crop Improvement 14 (1/2): 325-369. 